\title{
Radium annotated bibliography compiled in 1903 in the USA
}

\author{
Richard F. Mould
}

References compiled in the USA (as distinct from Europe) for the years to 1903 are contained in this bibliography. The summaries provide an interesting insight into the opinions and knowledge on radium which were held in the USA during the first few years after its discovery in 1898. The compiler of these references was almost certainly a professor of chemistry and mineralogist, Charles Baskerville (1872-1922) of New York. Some references are from academic scientific journals whereas others are from the popular scientific press. In these early years following the discovery of radium, publications and commentaries on them were far more in Europe than in the United States. This scientific fact gives some importance to this bibliography. I have retained the original spelling and punctuation used by Baskerville.

Key words: actinium, American Electro-Chemical Society, American Museum of Natural History, barium, barium platino-cyanide screen, Charles Baskerville, Henri Becquerel, bismuth, cathode rays, Sir William Crookes, Marie Curie, Andre Debierne, extraction of radium, fire flies, fusion of uranium and barium oxides, gems, Friedrich Giesel, glow worms, William Joseph Hammer, Charles Henry, Heinrich Hertz, Franz Himstedt, induced activity, Philipp Lenard, Sir Oliver Lodge, luminescence, minerals, New York Academy of Medicine, New York Electrical Society, phosphorescence, polonium, radium, radium paint, radon (radium emanation), Sir William Ramsay, Rontgen rays, Ernest Rutherford, Frederick Soddy, spectroscopy, spinthariscope, street lighting, thermoluminescence, Joseph J. Thomson, thorium, X-rays

\section{Introduction}

This bibliography compiled in the USA (as distinct from Europe) not only gives the full reference of a publication, but often also summaries of the contents or major conclusions. Most are dated 1903. These summaries provide a unique previously unpublished view of opinions concerning radium in the first five years since its discovery by Marie and Pierre Curie in 1898. Other bibliographies for this time period which have been published do not contain such summaries. It is virtually certain that the compiler of the references was Charles Baskerville (1872-1922) who was the author of the 1905 book Radium and Radioactive Substances their Application Especially to Medicine (published by Williams, Brown \& Earle, Philadelphia). Baskerville described himself in 1905 as Professor of Chemistry and Director of the Laboratory, College of the City of New York, formerly of the University of North Carolina. Those references without any attributable author are classified as Anon and are editorials, reviews or news items. Forenames are given for a few authors. In the early years following the discovery of radium, many more references were available in Europe and the availability of references in the USA was limited.

\section{Bibliography}

- Ackroyd, William. A new case of phosphorescence induced by radium bromide. Nature 1903; 68: 269-270. [Describes phosphorescence of common salt induced by contact with a tube containing radium bromide, and states that phosphorescence persists after removal of radium.]

- Begard, H. Les rayons de Becquerel et de Curie. Bulletin de la Societe Industrielle de Mulhouse 1901; 71:107-210. [General article similar to many others published at this time.] 
- Baur, E. Die bedeutung der Becquerel - strahlen in der chemie. Naturwisserschaftliche rundschau 1901; 16: 338-350, 355-356. [Repeats much of early material describes method of extracting radium and speaks of phosphorescent and inducing properties of the radiations.]

- Becquerel, H. Sur la radio-activite de la matiere. Proceedings of the Royal Institution 1902; 17:85-94, published 1906. [Account of work of himself and Curies.]

- Berthelot. Investigations of certain chemical reactions determined by radium. Scientific American supplement May 1902; 53: 22050-22051. [Relates to experiments where radium chloride was kept in a sealed tube.]

- Bolton, H.C. A new source of heat-radium. Popular Science Monthly May 1903; 63: 31. [Relates principally to heat emanations.]

- Bolton, H.C. A new source of light and of Rontgen rays. Popular Science Monthly July 1900; 57:318-322. [Popular article. Nothing to anticipate use of radium paint.]

- Crookes, Sir William. Modern views on matter: the realization of a dream. Science new series June 26 1903; 17: 993-1003. [Largely theoretical as to possible existence of a "protyle" or parent substance. Describes the spinthariscope. A convenient way to show these scintillations is to fit the blende screen at the end of a brass tube with a speck of radium salt in front about a millimetre to call this little instrument the 'spinthariscope' from the Greek word a scintillation. If a few minute grains of radium salt fall on the zinc sulphide screen the surface is immediately dotted with brilliant specks of green light.]

- Curie, Mme. The radio-active elements. Independent June 25 1902; 55: 1498-1503. [General description of investigations. Does not touch especially on induced luminescence.]

- Giesel, F. Polonium and radium. British Journal of Photography 1900; 47: 410-411. [Discusses and compares behaviour of polonium and radium. States power of exciting phosphorescence in zinc sulphide, fluorspar etc.]

- Giesel, F. Verhalten des radioactiven baryte und polonium. Annalen der physik und chemie new series 1899; 69: 91-94. [Work done independently of the Curies, as to the behaviour of radioactive compounds. The green salt of barium platino-cyanide produced from active barium chloride and potassium platino-cyanide with the addition of a small amount of potassium cyanide, phosphorescences very strongly of itself, as was to be expected. The luminosity becomes weaker in time, however, because gradually by the continued action of its own rays the green salt is transformed into the less sensitive yellow and finally into the brown salt, analogous to the behaviour of the ordinary barium platino-cyanide screen under continuous action of Rontgen rays. By dissolving the brown salt and renewed crystallization the green salt may be reproduced.]
- Giesel, F. Ueber den emanations - korper ans pechblende und ueber radium. Berichte der Deutschen Chemischen Gesellschaft 1903; 36, part 1, 342-347. [with translations]

- Giesel, F. Ueber polonium und die inducierende eigenschaft des radiums. Berichte der Deutschen Chemischen Gesellschaft 1903; 36, part 2, 2368-2370. [with translations]

- Giesel, F. Ueber radioactive substanzen und daren Strahlen. Sammlung chemischer und chemisch technischer 1902; 7: 1-28. Page 8. Fusion of uranium and barium oxides. [Von Lengyel obtained by fusing together uranium oxide and barium oxide in the electric arc, an active barium sulphate and believed that he had produced radium synthetically. I however have shown that the barium sulphate precipitated in the presence of uranium salt owes its activity not to the fusion process but to an active impurity of the uranium which behaves like actinium and like it may be separated from the barium. Pages 15-16. Phosphorescent effect. A large number of bodies are excited to phosphorescence by the intensively radiant preparations. It may only be mentioned that glass, many salts and minerals as well as organic compounds become luminous in the rays, especially strong are: barium platino-cyanide, uranium, potassium sulphate, Sidot blende, tungstate of lime, sodium naphthionate (Miethe); somewhat less fluorspar, diamond, cinchona bisulphate; liquids, also become luminous, e.g. water, fluorspar. If the latter (especially the colourless variety is heated it becomes luminous in intensely yellow-green light (as found by Becquerel and Giesel) which shows definite lines in the spectroscope; at last the light becomes violet. Fluorspar is also naturally themoluminescent, so it should be deprived of this property by previous heating. Uranium potassium sulphate shines continuously as a result of its active impurities but the phenomenon is so slight that it can be observed only when the eye has rested some time in darkness. Radium-containing barium salts shows self-luminescence more distinctly; the anhydrous bromide is especially strong. The slightest amounts of radium betray themselves by the phosphorescence of the dehydrated bromide. Upon heating, this phosphorescence fades but reappears on cooling. My preparations sealed in glass tubes have now for two years been spending their mysterious light which is perceptible even in semi-darkness. For this only radium preparations are necessary. Upon phosphorescent action, as I suspected and Himstedt has proved, depends the appearance of light which is perceived when a highly active preparation is brought near the closed eye or its vicinity. Page 26. Induced activity. The strongest and most lasting activity is obtained, as I had observed in connection with radium and bismuth and 
thorium, when the substance to be activated is left with the radioactive material in solution. Debierne in this way activated ordinary barium salts with actinium.]

- Guenther, Richard (Consul at Frankfort). The Becquerel rays. U.S. Consular Reports 1901; 66: 48. [Half a page concerning the nature and origin of Becquerel rays, stating their property of causing transparent substances to become luminous in the dark. Mentions great secrecy maintained in Germany about the results of experiments.]

- Hammer, W.J. Radium and other radioactive substances. Scientific American supplement 55; May 25 1903: 22904-22907. [Condensed report of lecture before A.I.E.E. and A.E.S. New York.]

- Hammer, W.J. Phosphorescence. From Translations of the American Electro-Chemical Society 1903; 3: appendix page 8.

- Henry, Charles. Preparation nouvelle et photometrie dus sulpue de zinc phosphorescent. Comptes rendus 1898; 117: 505-507. [with translation]

- Hofmann, K.A, Korn, A, and Strauss, E. Ueber die einwirkung von kethodenstrahlen auf radio-active substanzen. Berichte der Deutschen Chemischen Gessellschaft 1901; 34: 407-409. [Describes method of operation in making various substances fluorescent under influence of cathode rays.]

- Hofmann, K.A, and Strauss, Eduard. Ueber das radioactive blei. Berichte der Deutschen Chemischen Gessellschaft 1901; 34: 8-11. [Describes separation of a radioactive substance from the lead fraction of certain minerals such as pitchblende, Broggerite, deverite, etc. Preliminary paper. This substance became luminescent upon exposure to cathode rays.]

- Hoffmann, K. A. and Strauss, E. Ueber das radioactive blei. Berichte der Deutschen Chemischen Gessellschaft 1901; 34: 907-913. [Further experiments showing that the radioactivity was confined to the lead sulphate preparation.]

- Hoffmann, K.A. and Strauss, Eduard. Ueber das radioactive blei. Berichte der Deutschen Chemischen Gessellschaft 1901; 34: 3033-3039. [Continuous study of radioactivity. Describes phosphorescence from X-rays. (translation) In order to compare this with known phosphorescent substances (especially Balmain's luminous material) we exposed our sulphate for two months uncovered to the direct daylight but could perceive neither a strengthening $\mathrm{nr}$ a weakening of photographic activity. From this as well as from the penetration of aluminium foil is evidenced the difference between our preparation and the long-known phosphorescence of the alkaline earth sulphides. Our sulphate emits Becquerel rays.]
- Kanolt, C.W. Radium - its extraordinary properties. Scientific American 25 February 1903; 88: 149. [Mentions power of radium rays to excite phosphorescence in many things.]

- Kropotkin, P. Recent science. Unsuspected radiations. Nineteenth Century December 1900; 48: 919-933. [Discusses physical phenomenon connected with cathode, $\mathrm{X}$ - and Becquerel rays. Speaks of spontaneous glowing of phosphorescent screen on approach of radium.]

- Kunz, G.F. and Baskerville, Charles. The action of radium, Roentgen rays and ultra-violet light on minerals and gems. Science new series 18 December 1903; 18: 767-783. [Long article on results of experiments with numerous varieties of gems and minerals. This mentions the radium paint of radium bromide, zinc sulphide and oil.]

- Langley and Dery. The cheapest form of light. Smithsonian Miscellaneous Collections 1905; 41: publication 1258: 20. Study of luminosity of fire-fly, glow-worm etc. [Besides these biologic sources of light, there have been discovered several kinds of mineral matter possessing the extraordinary power of emitting visible, active and skiagraphic rays. Cites uranium compounds and discovery of radium and polonium. Rays given out by radium compounds exert chemical action, and they excite fluorescence in barium platino-cyanide screens.]

- Leenhardt, Charles. Etude de la radio-activite. Science au XXe siècle 15 May 1903; 1: 138-140. [Description of Rutherford's work with thorium, uranium and radium.]

- Legge, F. A new form of energy. Living Age April 1903; 236: 445-447. [Brief discussion mainly presenting various possible problems connected with radioactivity.]

- Lodge, Oliver. Radium and its lessons. Nineteenth Century July 1903; 54: 78-85. [Mentions induced activity of zinc blende.]

- Merritt, Ernest. Recent developments in the study of radioactive substances. Science new series 10 July 1903; 17:41-47. [Principally concerned with the nature of the emanations.]

- Moffett, Cleveland. The wonders of radium. McClure's Magazine November 1903; 22: 3-15. [Popular article.]

- Muthmann, W. and Bauer, E. Einige beobachtungen ueber luminescens spectrum. Berichte der Deutschen Chemisoen Gessellschaft 1900; 33: 1748-1765. [To return to the aforesaid question, it must be admitted that certain impurities influence the luminescence spectra in notable manner, increase, weaken or entirely prevent luminosity, alter the wave lengths of the bands etc. Lime and gypsum for example play a great part in that an addition of this substance increases the light power of yttria preparations about 10 to 20 times and causes the appearance of lines which are not seen with the pure preparations.] 
- Pegram, G.B. Radio-active substances and their radiations. Science new series 1901; 14: 53-59. [Describes early experiments and theories regarding radium.]

- Ramsay, William. The Becquerel rays. Contemporary Review May 1902; 81: 730-740. [Discusses the history of discovery of various radioactive substances. Mentions early attempt to utilize phosphorescent material in luminous paint, and fact that sulphide of zinc greatly increases effect of X-rays. It is true that investigators like Hertz, Lenard, Becquerel and the Curies do not make practical application of their discoveries; but there is never any lack of men who discover their practical value and apply them to ends useful to mankind.]

- Rutherford, E. Radioactivity produced by thorium compounds. Philosophical Magazine $5^{\text {th }}$ series 1900; 49: 161-192. [Experiments as to cause and characteristics of radioactivity.]

- Rutherford, E. and Brooks, H.T. The new gas from radium. Transactions of the Royal Society of Canada $2^{\text {nd }}$ series 1901; 7:21-25. [A study of the radium emanations.]

- Rutherford, E. and Soddy, F. The radioactivity of thorium compounds. II The cause and nature of radioactivity. Journal of the Chemical Society, London 1902; 81: 837-860.

- Shenstone, W.A. Radium. Living Age 18 July 1903; 238: 12-137, [Good article, mentions induced phosphorescence of barium platino-cyanide and of zinc sulphide.]

- Sidot, T. Sur les proprieties de la blende hexagonale. Comptes rendus 1866; 63: 188-189. [with translation]

- Soddy, Frederick. Recent advances in radioactivity. Contemporary Review May 1903; 83: 708-720. [Account of the researches of Rutherford and his workers. Discusses possible nature of emanations, excited activity, probable energy losses, etc.]

- Thomson, J.J. Becquerel ray. Harper's Magazine January 1903; 106: 289-293. [Discussion of sources and behaviour of the rays emitted by various radio-active substances.]

- Thorp, Thomas. Radium. English Mechanic and World of Science 28 August 1903; 66-67.

- Visser, L.E.C. de. Essai d'une theorie sur la phosphorescence de longue duree, specialement sur celle des sulfures alcalino-terruz. Recuil des travaux chemique des Pays Bas et de la Belgique 1901; 20:435-456. [Phosphorescent sulphides of alkaline earths prepared and studied. Discovery that addition of small amounts of bismuth greatly increased phosphorescent properties of mixture. Bismuth added to solution.]

- Walker, J.B. A new field for speculation. Cosmopolitan 1902; 33: 524-525. [Popular article mentions uses of radium. Some have estimated that but a small weight of radium would furnish a light for economic purposes so brilliant that the human eye and body wold have to be protected from its influence. Once in place, however, it would be installed for all time. Article preceded by Prize Offer for best paper on radium to be received before 1 January 1903.]

- Walsh, G.E. A new light for the world; radium light and heat rays. New England Magazine new series October 1903; 29: 247-253. [Popular article - no disclosure of use as paint.]

- Watties, Cyr. Radium and its recent development. Scientific American supplement, 56: 25 July 1903; 23042. [Monograph translated from L'Industrie Textile, collected from numerous sources. Describes exciting of luminescence of zinc or calcium sulphide by means of radium.]

- Wiedemann, E. Thermoluminescens durch radiumstrahlen. Physikalische Zeitschrift 1901; 2: 259. [Describes exciting of thermoluminescence in a solid solution of $\mathrm{CaSO}_{4}+\mathrm{MnSO}_{4}$ by placing radium on solution.]

- Anon. New sources of light. Review of Reviews August 1900; 22: 229-230. [Review of article by Bolton in Popular Sciences Monthly July 1900.]

- Anon. Latest lamps: mysterious sources of light. Current Literature 1901; 30: 441-443. [First describes generally (and not very accurately) radium and its properties. Another article describes a luminous object at the Paris exposition - the so-called "eternal" light. I have one of the experimental tubes besides me at the moment, a mere toy it must be confessed, a trifle that cost 20 cents. It is a hermetically closed glass tube about 4 inches long, and, say a quarter of an inch in diameter. Inside of it, running its whole length, is a thin stick of glass having 9 little circular glass "shelves" or projections that almost but not quite touch the inside surface of the tube. Running loose in the tube, unconfined, is a small quantity about half a thimbleful of mercury. While the whole scientific theory of this thing is kept absolutely secret, one is informed that the glass stick and shelves inside of the tube are "uraniumised" or composed of glass mixed with uranium. Agitate it in a dark room and immediately this glittering becomes a bright phosphorescent light.]

- Anon. Selbstrahlande substanzen. Dinglers Polytechnische Journal 1902; 317: 161-162. [General article discussing possible explanatory theories and describing various properties of radioactive substances.]

- Anon. Costly particles of radium. New York Times February 20 1903; page 6, column 6. [Item as to Hammer's talk before the Academy of Medicine, where he exhibited tubes containing small particles of radium.]

- Anon. The mystery of radium. London Times March 25 1903; page 10, column 4. [Editorial relating to discovery by the Curies of the emission of heat by radium compounds.]

- Anon. Radium in Connecticut. New York Times 12 April 1903, page 1 column 4. [Note that a Boston mineralogist has small tube containing a rough whitish powder, a bit of radium chloride.] 
- Anon. Radium - the wizard metal. Harper's Weekly 25 April 1903; 47: 677-679. [Describes radiation and mentions induced luminescence.]

- Anon. Possibilities of radium. New York Times 21 May 1903, page 8 column 6. [Report of talk by Hammer before New York Electrical Society 20 May. Included talk on phosphorescent substances.]

- Anon. Radium. English Mechanic and World of Science 29 May 1903; page 341.

- Anon. Radium. British Journal of Photography 29 May 1903; 50: 432-433. [Mentions various properties, such as emission of light and heat, and physiological effects. It is asked, 'What is the use of all this?' One can only answer more Scittio. 'What is the use of a baby?' As baby it is not of any use, in fact it is a nuisance. But it will grow into a man, who is of use. In the same way it is not easy to say that radium is at present of any use from the strictly practical stand-point. It might perhaps, be used homeopathically for the cure of photopsia, which, as we have just seen, it causes. If we had plenty of it, we might paint London with calcium sulphide, put radium in the street lamps and get a mild moonlight everywhere, while saving on gas and electricity. But people careful of their complexions might object to its effect upon the cuticle. No, it cannot be said at present to be extensive practical utility. But it is only a baby, and in developing or knowledge of it were are very likely to hit upon something useful, or upon something that just gives the hint required to make some other piece of knowledge useful.]

- Anon. Nature 30 July 1903; 68: 302. [Mr F.W. Branson of Leeds sent us an account of some experiments made by him with a mixture of radium and barium chloride in a dry and in a moist state.]

- Anon. Radium in England. Popular Science Monthly August 1903; 63: 381-382. [Describes exhibition in London where $\mathrm{R}-\mathrm{A}-\mathrm{D}-\mathrm{I}-\mathrm{U}-\mathrm{M}$ has been painted with radium bromide on a screen of hexagonal blende which becomes luminous when brought near a compound of radium.]

- Anon. Crowds see radium. New York Tribune 8 September 1903, page 3 column 5. [Describes specimen exhi-bited at American Museum of Natural History "a tiny tube containing a fine grey powder".]

- Anon. A possible use for radium. Science new series 11 September 1903; 18: 338. [Brief paragraph suggesting possibility of using radium as a source of light. Refers to Daily Graphic where analogy to luminous insects is pointed out.]

- Anon. The revelations of radium. Living Age 5 December 1903; 239: 577-594. [Has numerous bibliographical references, concerned largely with describing various physical and theoretical matters.]

- Anon. Proceedings of Societies. The Royal Society (Chemical News) 1903; 8: 245-246. [Radium]

Conflict of interest: none declared

\section{Richard F. Mould, MSc, PhD}

4, Town End Meadow

Cartmel

Grange-over-Sands

Cumbria LA116QG

United Kingdom

e-mail:manorroadsouthport@yahoo.co.uk

Received \& Accepted: 23 May 2018 